Praxis Essay

\title{
Enhancing the Intercultural Competence of College Students: A Consideration of Applied Teaching Techniques
}

\author{
Brian W. Haas \\ University of Georgia
}

U. S. A.

ABSTRACT: Many higher education instructions have set forth explicit objectives to improve college students' intercultural competence. However, there currently exists considerable heterogeneity in terms of the extent and methods that higher education institutions apply in order to achieve this important goal. This praxis essay provides a framework to understand the process of intercultural learning in college students and provides examples of specific teaching techniques that can be used to enhance intercultural competence in college students. Examples are provided that include lectures based on cultural psychology, group discussions on the value of diversity on outcomes related to creativity and innovation, and a cross-cultural interview project. This article is designed to provide guidance paired with examples of specific teaching techniques that target specific intercultural learning areas.

KEYWORDS: Intercultural learning, Intercultural competence, Cultural psychology, Higher education, Pedagogy

The Process of Intercultural Learning Cultural Psychology as an Academic Field Intercultural Learning in Cultural Psychology Conclusion References Author Contact

The ability to communicate effectively and appropriately with people of other cultures is a highly desirable and valuable skill to have. People who are more adept at navigating through complex intercultural situations show improved job performance and tend to impact their colleagues positively (Leung, Ang, \& Tan, 2014). The primary role of higher education is to prepare students to be successful within their careers. Thus, providing specific intercultural learning-based curriculum to college students is an extremely important endeavor for higher education institutions (Deardorff, 2009; Lee, Poch, Shaw, \& Williams, 2012). One method by which higher education institutions may be able to facilitate intercultural learning in a broad range of students is to offer a course involving major themes of cultural psychology. Cultural psychology is the explicit study of how 
psychological and behavioral tendencies are embodied in a particular nation, people, or other social group. Learning about cultural psychology may be a particularly effective method to increase college students' intercultural competence.

Intercultural competence (IC) is conceptualized in several ways. According to Van der Zee and van Oudenhoven (2000), IC is comprised of (a) openmindedness, (b) cultural empathy, (c) emotional stability, (d) flexibility, and (e) social initiative. Stone (2006) partitioned IC into emotional intelligence, cultural knowledge, motivation, openness, resilience, reflectiveness, sensitivity, and skills (e.g., in oral communication). For purposes of clarity and consistency with existing literature, the following working definition was adopted from King \& colleagues and will be used as the basis of this essay (2007): "Knowledge of cultures and cultural practices (one's own and others'), complex cognitive skills for decision making in intercultural contexts, social skills to function effectively in diverse groups, and personal attributes that include flexibility and openness to new ideas." It should be noted that this working definition of IC allows for the inclusion of other constructs referred to as "intercultural effectiveness," "multicultural competence," and "cultural intelligence."

A great deal of evidence demonstrates that higher IC confers a broad range of positive outcomes for individuals and social groups (Leung et al., 2014). People with higher IC tend to be more engaged in self-directed learning (Chuprina, 2002) and experience more psychological well-being (Ward, Wilson, \& Fischer, 2011) and less stress (Redmond, 2000; Redmond \& Bunyi, 1993) as compared to people with lower IC. Within dyads, higher IC is associated with enhanced trust and creative collaboration (Chua, Morris, \& Mor, 2012) and more information intergration behaviors during negotiations (Imai \& Gelfand, 2010). Furthermore, higher IC is positively associated with a variety of job performance outcome measures (Mol, Born, Willemsen, \& Van Der Molen, 2005; Shi \& Franklin, 2014; Simkhovych, 2009). Together, these studies demonstrate the broad scope of work and career-related advantages associated with improved IC and highlight the importance of promoting IC in college students.

This article reports on the compilation and synthesis of existing published research on intercultural learning. A literature search was conducted and the findings across several studies were considered. In addition, practical examples of teaching techniques were compiled and reported based on my first-hand experience teaching cultural psychology to many students within a college setting. This article begins by providing a framework to understand the process of intercultural learning. I then review the core features of academic cultural psychology. Lastly, I provide recommendations for implementing a cultural psychology course to a broad and diverse range of college students.

\section{The Process of Intercultural Learning}


Intercultural learning is the process of gaining the skills and knowledge necessary to function effectively in cross-cultural situations. Intercultural learning is a dynamic process that occurs throughout the lifespan. Through the process of intercultural learning, people may improve their IC. Because IC is dynamic and malleable, as opposed to a stable trait, specific learning-based objectives can be set (Strohmeier, Gradinger, \& Wagner, 2017). Through this "incremental" approach, IC can either increase, decrease, or remain the same in response to effort and/or experience. As an initial step towards the design of effective teaching and training techniques, it is important to outline specific, targeted, learning-based outcomes.

What does one need to learn in order to become interculturally competent? One way to categorize IC capabilities is to differentiate between knowledge and skills, knowledge referring to information and attitudes, skills referring to a set of behavioral capabilities.

An important area of knowledge is the understanding that humans are, at their core, social beings and that individuals or groups of people are not immune to the influences of other people (i.e., culture) on their mental processing and behavior. Furthermore, it is important to understand the magnitude and scope of influence and to see the "self" as an amalgamation of both internal and external influences. This knowledge provides a grounding to understand further that people possess different worldviews according to whom they interact with and what they have experienced. A key component of knowledge is to see how contextual factors influence mental processing, to understand that the human mind is influenced by external context. Put another way, it is important to consider the mind as interdependent within external context as opposed to independent of external context.

Another important knowledge area for IC is the understanding that cultures are, by definition, dynamic and organic entities. Cultures are constantly in flux and their features are also not immune to the influences of context and experience. Cultures, just as the human mind, possess interdependent relationships with other cultures. Furthermore, the functional units within any culture are living, breathing, growing, thinking, and feeling entities (i.e., human beings). Thus, it follows that cultures are also dynamic and changing entities. Providing this grounding lays the framework to understand that each person is not only a recipient of culture, but also an active agent and contributor within culture, and possesses the ability to shape and influence that culture. This grounding can lead to the understanding of core principles of multiculturalism. In particular, by understanding the interdependent nature of cultures, one can recognize how multiple cultures can influence one's worldview, and that cultures are not defined by distinct boundaries. One may live and develop in one particular culture, but this does not necessarily exclude the influence of other cultures on shaping one's worldview. This understanding leads to accepting that humans are, more often than not, multicultural entities. 
IC also includes knowledge about the way cultural diversity influences social group dynamics. A core feature of this knowledge area is the understanding that alternative perspectives and abilities often positively impact the way social groups work, especially when creativity and innovation are desired outcomes (Earley \& Mosakowski, 2000; Stahl, Maznevski, Voigt, \& Jonsen, 2010). Initially, an understanding can be built based on the distinction between problem solving in isolation versus problem solving as a team. With this established, one may recognize the relative advantages associated with a team comprised of members with heterogeneous backgrounds and skill sets versus a team comprised of members with homogeneous backgrounds and skill sets. This understanding facilitates the recognition of cultural diversity as an asset, as opposed to a burden or an element in need of "management." Knowledge of the function and usefulness of cultural diversity can influence attitudes related to global relativism and citizenry. As opposed to ethnocentrism, cultural relativism is the understanding that a person's belief's, values, and practices are largely based on a person's culture. Global citizenry is the understanding that one's identity transcends geography or political borders and that responsibilities and rights are derived from membership in a broader class, that is, "humanity" (McFarland, Webb, \& Brown, 2012; Wynveen, Kyle, \& Tarrant, 2012).

It is also important to understand the common barriers that tend to impede the process of gaining IC. One clear barrier is the natural tendency for humans to self-enhance. Humans tend to interpret or distort evidence about themselves in order to amplify a relatively positive self-image (Beauregard \& Dunning, 1998; Krueger, 1998; Sedikides \& Strube, 1995). This means that humans tend to be biased in ways that favor themselves. This bias not only manifests favoring the characteristics of one's self, but also the characteristics of other people that are more similar to one's self. In the scope of intercultural learning, this bias presents a clear barrier to overcome when one is working towards functioning effectively with people who think, feel, and behave differently from one's self and differently with respect to one's heritage culture. By understanding this innate, natural tendency of humans, one may be better positioned and motivated to adopt strategies to counteract self enhancement bias effectively. In support of this, empirical research shows that when people are informed of their own racial biases, they become more motivated and are subsequently more successful in reducing their own prejudice (Amodio, Devine, \& Harmon-Jones, 2007). A key step towards reaching IC is gaining an awareness of humans' universal natural tendencies and one's own particular biases and tendencies (i.e., self-awareness).

Gaining IC also involves acquiring a set of skills or behavioral capabilities. IC involves developing a set of complex cognitive skills for decision making within intercultural contexts and social skills to function effectively within diverse groups. Some of these skills include theory of mind/perspective taking, empathy, resilience, flexibility, emotional stability, and emotion regulation. Empirical research shows that many of these skills are dynamic, malleable processes that can change according to structured training and in response to experience. For example, theory of mind and perspective taking improves as a result of reading fiction (Kidd \& Castano, 2013) and structured training (Santiesteban, White, Cook, Gilbert, 
Heyes, \& Bird, 2012) and empathy and emotion regulation improves as a result of meditation and mindfulness-based training (Shapiro, Schwartz, \& Bonner, 1998).

Another behavioral skill comprising IC is social flexibility, which is the ability to modify ideas and behavior, to compromise and to be receptive to new ways of doing things (Kealey, 1996). Being socially flexible provides one with the ability to be adaptable across a wide range of cultural contexts (Bird, Mendenhall, Stevens, \& Oddou, 2010).

Cross cultural communication is also an important skill area part of IC. This includes non-verbal (e.g., gestures and facial expressions) and verbal (e.g., languages, accent and tone) skills. It is important for students to learn the skill of adapting their means of communication to the cultural context they are currently in. For example, making direct eye contact when speaking with other people can be interpreted in different ways according to cultural context (Akechi et al., 2013). Learning different languages and developing the ability to modify communication style according to contextual cues positions one to function more effectively across cultures.

It is important to note however that the extent of change in each skill area is in large part contingent upon the amount of one's desire and motivation to change. Creating a learning environment in which students are inspired and curious is an extremely important component in facilitating intercultural learning. Overall, these findings provide a solid grounding in order to design training techniques and structured activities to promote the learning of specific IC-related knowledge areas and skills.

Meanwhile, Bennett's (1986) Developmental Model of Intercultural Sensitivity has advanced the way the process of intercultural learning is understood. In this model, Bennet outlines specific sequential developmental stages, modeling them such that reaching subsequent stages is contingent upon the completion of the lower stages. The first stage, Denial of Difference, is characterized by extreme ethnocentrism. Individuals in this stage consider their heritage culture as the only "real" culture, and actively avoid learning or experiencing cultural differences. The second stage, termed Defense against Difference, is characterized by understanding other cultures' characteristics but actively and openly devaluing them. The third stage, Minimization of Difference, is characterized by the belief that cultures tend to differ in terms of superficial characteristics such as with rituals or food, but that cultures do not tend to differ in terms of more complex characteristics such as values and psychological needs. The fourth stage, Acceptance of Difference, is characterized by an active willingness or pursuit to gain knowledge of culturally different ways of organizing human existence. The fifth stage is Adaptation to Difference, characterized by an ability to use empathy and theory of mind to understand and be understood across cultural boundaries. The sixth and final stage, Integration of Difference, is characterized by a view of self that is malleable and is able to transcend cultural boundaries. 
Bennett (1986) also provides some guidelines to consider in terms of effective training approaches to facilitate IC development. He describes that exposure to other cultures, paired with guided discussions, is an effective initial step. Exposure may be in the form of readings such as ethnographies, or local events that include representative music, food, or other customs from another culture. Next, to develop from the Defense against Difference stage, one can focus on the "generally good" aspects of several other cultures, including one's own. Other approaches include learning about other cultures from individual representative people, exposure to evidence that variability of values across cultures exists, facilitated multicultural group discussions, and one-on-one interviews with people from other cultures. These approaches are commonly incorporated in intercultural training techniques implemented within a wide array of settings (Perry \& Southwell, 2011) and have been incorporated into other important models of IC development, such as King and Baxter Magolda's Developmental Model of Intercultural Maturity (King \& Baxter Magolda, 2005; Perez, Shim, King, \& Magolda, 2015).

Within higher education settings, college students tend to experience intercultural learning in a variety of ways. King, Perez, and Shim (2013) reported on the results of a qualitative research study on semi-structured interviews of college students. Students were interviewed about how they gained knowledge and meaning related to intercultural learning. Thematic coding of the resulting interview data demonstrated that college students tend to experience intercultural learning when directly encountering others' experiences, feeling safe enough to explore cultural differences, observing cultural differences, comparing and contrasting other people's experiences with one's own, engaging in personal reflection, and exploring one's own personal identity. Each of these experiences tends to occur in a variety of college-life settings that include academic courses, study abroad trips, service-learning programs, and club activities and friendships. The following sections explore how cultural psychology, as an academic field, provides an avenue for students to actively engage in intercultural learning experiences.

\section{Cultural Psychology as an Academic Field}

Cultural psychology involves the explicit investigation of the way culture shapes mental processing. Within this definition, culture is further defined as a set of ideas that coordinates the actions and influences the views and meanings held by a group of people. Thus, culture may be descriptive of shared ideas and values on a local scale, such as within a group of friends, or on a global scale, such as the entire human population on the earth. Culture describes shared meaning systems that typically guide behavior.

As an academic field, cultural psychology is typically conceptualized under the umbrella of general psychology. This is evidenced by the fact that cultural psychologists and existing cultural psychology courses are typically within the 
psychology departments of higher education institutions. However, several core features of cultural psychology, such as social learning theory, are often dealt with within many humanities courses outside of psychology. There exist many inherent commonalities between traditional or general psychology and cultural psychology. First and foremost, all involve the goal of understanding how people think, feel, and behave. Also, many cultural psychologists use methods that have been developed or refined within traditional academic psychology research settings.

However, cultural psychology deviates from general psychology in several ways. Ideologically, general psychology tends to conceptualize the human mind as functioning independently from context and is thought of as the driving force that guides and shapes experience. Conversely, cultural psychology views the human mind as maintaining an interdependent relationship with context and acknowledges that the environment strongly guides and shapes experience. Furthermore, general psychology tends to prioritize evidence of human universals, while cultural psychology seeks to understand both human universals and culturally specific patterns of mental processing.

Although cultural psychology is typically housed within psychology departments, many ideological characteristics and research methods overlap with other traditional academic disciplines. For example, one key area of investigation in cultural psychology is how cultural ideas develop and change over time, which is also an important research area within cultural anthropology. Cultural psychologists are also interested in how groups of people, within societies or cultures, function and behave, which is a central research area within sociology. Furthermore, cultural psychologists seek to understand the way language shapes meaning across cultures, which is a central research area within linguistics and communication. Because cultural psychology deals with topics relevant to a broad range of other disciplines, a cultural psychology course is well suited for students with minimal prior education in psychology or those without explicit goals to obtain careers in psychology. In the following section, specific examples of teaching techniques are considered. These techniques are designed to leverage themes from the academic discipline of cultural psychology to enhance the intercultural learning of a broad and diverse range of college students (majors and non-majors alike).

\section{Intercultural Learning in Cultural Psychology}

A cultural psychology course is an excellent tool to improve college students' intercultural learning. In spite of many explicit objectives set forth by institutions of higher education to prepare college students for multicultural careers and experiences (Deardorff, 2009; Lee et al., 2012), there is no clear consensus across college curriculums in the United States to require undergraduate students to complete coursework on cultural issues, multiculturalism, and/or diversity. According to a nationally representative survey of 325 Chief Academic Officers of the Association of American Colleges and Universities (AAC\&U), 52\% of 
institutions require their students to complete a course on global or world culture studies, and $34 \%$ require students to complete a course on diversity studies (Hart Research Associates, 2016). There are a scant number of training opportunities for college students to improve IC.

Intercultural learning involves specific knowledge areas and developing skills. Table 1 provides a summary of key studies and teaching activities used to target each intercultural learning area. Within a cultural psychology course, college students should learn the extent to which humans tend to be social. This type of learning can be achieved by discussing evolutionary evidence that sociability was a key determinant of the development of human brain size. For example, Dunbar (1992) found that social group size was more predictive of primate neocortex size, as compared to tool use or type of diet. In class, students can be divided in groups and asked to conduct a thought experiment (TE) in which each group of students is asked to develop a ranked list of factors they believe are associated with increased brain size in primates and humans (as compared to other mammals). After lists are developed and discussed, empirical evidence is presented to the class a whole supporting the associating between social group size and neocortex size (Dunbar, 1992).

Another way to facilitate student learning about social influence and sensitivity is to conduct an in-class activity on conformity. For example, a great deal of empirical research has demonstrated the tendency of humans to make decisions in accordance with other people around them. In a classic social psychology experiment, Asch and Guetzkow (1951) demonstrated that people tend to choose obviously wrong answers when responding among a group of other people who select the wrong answer. As an activity, students who are in class immediately prior to the start of the lecture can be asked to select the wrong answer later on in class. Then, after other "naïve" students have arrived, a mock experiment can be conducted in class. As a follow-up, a video clip of people conforming to the direction of standing within an elevator can be shown and subsequently discussed in class.

Cultural psychology is an effective platform for learning that cultures are dynamic, changing, and organic entities. One way this can be achieved is through a class discussion on accepted norms and values of our grandparents' generation as compared to contemporary accepted norms and values. This discussion should serve to reveal specific examples showing that attitudes and behavioral tendencies tend to change over the course of a single generation. In addition, students can be presented with empirical research demonstrating that many constructs that include intelligence, self-esteem, gender equality, and individualism have changed within recent decades throughout the world (Varnum \& Grossmann, 2017).

Table 1. Intercultural Learning Areas and Classroom Activities

$\mathrm{K}=$ Knowledge; $\mathrm{S}=\mathrm{Skills} ; \mathrm{TE}=$ Thought Experiment $\mathrm{CD}=$ Class Discussion; $\mathrm{ME}=$ Mental Exercise.

\begin{tabular}{l|l|l} 
Intercultural learning & Key studies & Activities
\end{tabular}




\begin{tabular}{|c|c|c|}
\hline area & & \\
\hline $\begin{array}{l}\text { Humans as social } \\
\text { beings }(\mathrm{K})\end{array}$ & $\begin{array}{l}\text { Asch \& Guetzkow (1951) } \\
\text { Dunbar (1992) }\end{array}$ & $\begin{array}{l}\text {-TE: What factors led to } \\
\text { increased brain size in } \\
\text { primates and humans? } \\
\text {-Conformity and line length } \\
\text { experiment }\end{array}$ \\
\hline Cultures as dynamic (K) & $\begin{array}{l}\text { Barsade (2002) } \\
\text { Cullum \& Harton (2007) } \\
\text { Varnum \& Grossmann (2017) }\end{array}$ & $\begin{array}{l}\text {-CD: Norms and values of } \\
\text { grandparents' generation } \\
\text {-Building drawing small group } \\
\text { activity }\end{array}$ \\
\hline Multiculturalism (K) & $\begin{array}{l}\text { Apfelbaum, Pauker, } \\
\text { Sommers, \& Ambady, } \\
\text { (2010) } \\
\text { Crotty \& Brett (2012) } \\
\text { Mahajan \& Wynn (2012) }\end{array}$ & $\begin{array}{l}\text {-ME: New job welcome } \\
\text { message } \\
\text {-CD: Cultural diversity and } \\
\text { creativity }\end{array}$ \\
\hline Common barriers $(\mathrm{K})$ & $\begin{array}{l}\text { Amodio et al. (2007) } \\
\text { Fu, Tarnita, Christakis, } \\
\text { Wang, Rand \& Nowak } \\
\text { (2012) } \\
\text { Mahajan \& Wynn (2012) }\end{array}$ & $\begin{array}{l}\text {-In-group bias class activity } \\
\text {-CD: Infants and self-serving } \\
\text { bias }\end{array}$ \\
\hline $\begin{array}{l}\text { Perspective-taking, } \\
\text { openness and } \\
\text { empathy }(\mathrm{S})\end{array}$ & $\begin{array}{l}\text { Kidd \& Castano, (2013) } \\
\text { Shapiro, Schwartz \& } \\
\text { Bonner (1998) } \\
\text { Zimmermann \& Neyer (2013) }\end{array}$ & $\begin{array}{l}\text {-Letter home activity } \\
\text {-Interview project }\end{array}$ \\
\hline
\end{tabular}

In-class activities can be used to illustrate the concept that all individuals are active agents in shaping and influencing culture. For example, in a small group activity, specific roles can be given to individual students to collaborate with one another in order to design a new building at their university. Their goal is to draw how the building may look. Prior to the task, students are given cards that designate which group they will work in as well as their role (drawer, reporter and creative expert). One card for a single student (creative expert) in each group also includes a brief description of one of two "approaches." One approach is to advocate for a building that is large and functional, while the other is to advocate for a building that is small and aesthetically pleasing. At the end of the activity, the drawings from the groups with the "large and functional" social agents are compared to the drawings from the groups with the "small and aesthetically pleasing" social agents. This activity can be followed by a presentation of empirical research demonstrating how emotion and ideas are contagious and flow throughout a group of people (Barsade, 2002; Cullum \& Harton, 2007).

There are many ways to educate students about the influence of cultural diversity on social group dynamics. One important distinction to make is between multiculturalism and color-blind approaches. A multicultural approach supports the 
attention to and respecting of the distinctive aspects of different cultural, racial, and ethnic groups, while a colorblind approach supports looking beyond other peoples' culture and their racial and ethnic characteristics in an effort to focus on their common human nature. One way to educate students about these topics is through mental exercises (ME). In one ME, for example, students are first asked to identify for themselves where they were born, where their parents grew up, what types of hobbies they had during high school, and where they went to college. Next, students are asked to imagine themselves starting a new job. Then they are read two different potential "welcoming messages" as follows:

Scenario A: Welcome to your new job! Here, at this company, we believe that everyone is the same. This means that while you are at work it is preferred that you do not discuss personal things related to your identity with your coworkers. Please refrain from discussing things with your coworkers, such as where you were born, where your parents grew up, what your hobbies were while you were growing up, or where you went to college.

Scenario B: Welcome to your new job! Here, at this company, we believe that each person is unique and brings something special to our team. This means that we encourage you to express yourself and talk about your identity. We encourage you to feel comfortable discussing things with your coworkers, such as where you were born, where your parents grew up, what your hobbies were, or where you went to college.

The goal of this exercise is to elicit a conflicted feeling. Specifically, this exercise is designed to illustrate how it may feel when key characteristics of their identity are not acknowledged or valued. This in-class activity can be followed by a class discussion of empirical evidence demonstrating the way multicultural philosophies impact children's perspectives of prejudice (Apfelbaum et al., 2010) and minorities' psychological commitment to their place or work (Plaut, Thomas, \& Goren, 2009). Lastly, a class discussion can be led on the association between the cultural diversity of groups and creative performance (Crotty \& Brett, 2012).

In-class activities and class discussions (CD) can be conducted to improve students' knowledge of human's natural tendency towards in group favoritism and self-enhancement. Group activities and discussions can be led based on empirical findings indicating in-group favoritism (Fu, et al., 2012). For example, students can be divided into two groups using an arbitrary characteristic (e.g., wearing jeans vs. not wearing jeans). Then, groups are asked to generate a list of why the members of the other group chose to either wear or not wear jeans. As a follow-up, empirical evidence demonstrating that children as well as infants show tendencies towards self-serving biases can be presented and discussed (Mahajan \& Wynn, 2012). Lastly, these studies can be discussed within the context of empirical research showing that when people are informed of their own racial biases, they become 
more motivated and are subsequently more successful in reducing their own prejudice (Amodio et al., 2007).

In-class activities and out of class projects can be used to build a set of IC related skills and behavioral capabilities. One activity well suited to encourage students to practice thinking through the perspective of someone else (i.e., perspective-taking) is to read an ethnography about a culture very different from one's own. Next, students can be assigned to imagine being a person from this different culture and immigrating to where the student currently lives. Lastly, the student can be assigned to write a letter home explaining the process of acculturating to this "new" culture.

A cross-cultural interview project is also well-suited to practice, train, and improve perspective-taking. This interview project involves students being assigned to interview someone who has spent over $50 \%$ of his or her life outside of the student's home country. One way to structure this project is to perform a collective brainstorming session in class with students to develop a subset of interview questions. Questions can be developed that reflect students' understanding of cultural variation around the world, such as with individualismcollectivism, patriarchal-matriarchal, and issues related to diversity and acculturation. Students are then assigned to make contact with their interviewee, conduct the interview, and then write a reflection paper based on the entire experience. This project holds the potential to improve several IC-related skills such as theory of mind/perspective taking, empathy, and flexibility.

The letter home and interview project can be paired with discussion of ways people can work towards improving their perspective taking, openness to experience, and empathy. Some examples include reading fiction (Kidd \& Castano, 2013), living abroad (Zimmermann \& Neyer, 2013) and mindfulness-based training techniques (Shapiro, Schwartz, \& Bonner, 1998).

These methods may serve as effective ways to teach cultural psychology to a broad range of college students, including psychology majors and non-majors alike. The inclusion of in-class activities and discussions holds the potential to increase students' willingness to share personal experiences and learn from one another. As demonstrated by King and colleagues (2013), intercultural learning in college students tends to occur when they feel safe enough to explore cultural differences.

\section{Conclusion}

In spite of many clear objectives set forth by higher education institutions to improve students' intercultural learning, there remains considerable heterogeneity in the means and the extent that intercultural learning occurs within higher education. Because of increased globalization and the movement of many people across countries, it is paramount that the next generation of people within our world and work force possess the skills to function effectively in cross-cultural and multicultural contexts. 
Intercultural learning often occurs through experience paired with guidance. The college classroom presents a valuable opportunity for instructors to enhance their students' intercultural learning. Several specific techniques can be used to improve students' intercultural learning ranging from cultural psychology-focused lectures to group discussion and cross-cultural interview projects. By leveraging empirical research on the process of intercultural learning and the components of intercultural competence, educators may be better positioned to use cultural psychology-related pedagogy to prepare college students for their careers within a multicultural world.

Cultural psychology is an academic course well suited to provide college students with the necessary knowledge and skills to become more interculturally competent. The specific teaching techniques described here may serve as a framework to continue to build and improve how educators engage with students and promote their intercultural learning. Furthermore, this essay serves as a call to action for educators across disciplines to experiment with various multicultural teaching techniques. In the future, it will be important to employ qualitative and quantitative research methods to investigate the way cultural psychology-related pedagogy affects specific intercultural learning-related outcomes. While qualitative research can guide theory and practice, quantitative research provides the opportunity to compare learning outcomes statistically between different intercultural teaching techniques.

\section{References}

Akechi, H., Senju, A., Uibo, H., Kikuchi, Y., Hasegawa, T., \& Hietanen, J. K. (2013). Attention to eye contact in the West and East: Autonomic responses and evaluative ratings. PloS one, 8(3), e59312.

Amodio, D. M., Devine, P. G., \& Harmon-Jones, E. (2007). A dynamic model of guilt: Implications for motivation and self-regulation in the context of prejudice. Psychological Science, 18(6), 524-530.

Apfelbaum, E. P., Pauker, K., Sommers, S. R., \& Ambady, N. (2010). In blind pursuit of racial equality? Psychological Science, 21(11), 1587-1592.

Asch, S. E., \& Guetzkow, H. (1951). Effects of group pressure upon the modification and distortion of judgments. Documents of Gestalt Psychology, 222-236.

Barsade, S. G. (2002). The ripple effect: Emotional contagion and its influence on group behavior. Administrative Science Quarterly, 47(4), 644-675.

Beauregard, K. S., \& Dunning, D. (1998). Turning up the contrast: Selfenhancement motives prompt egocentric contrast effects in social judgments. Journal of Personality \& Social Psychology, 74(3), 606-621.

Bennett, M. J. (1986). A developmental approach to training for intercultural sensitivity. International Journal of Intercultural Relations, 10(2), 179-196. 
Bird, A., Mendenhall, M., Stevens, M. J., \& Oddou, G. (2010). Defining the content domain of intercultural competence for global leaders. Journal of Managerial Psychology, 25(8), 810-828.

Chua, R. Y., Morris, M. W., \& Mor, S. (2012). Collaborating across cultures: Cultural metacognition and affect-based trust in creative collaboration. Organizational Behavior and Human Decision Processes, 118(2), 116-131.

Chuprina, L. A. (2002). The relationship between self-directed learning readiness and cross-cultural adaptability in United States expatriate managers (Doctoral dissertation). Available from ProQuest Information \& Learning.

Crotty, S. K., \& Brett, J. M. (2012). Fusing creativity: Cultural metacognition and teamwork in multicultural teams. Negotiation and Conflict Management Research, 5(2), 210-234.

Cullum, J., \& Harton, H. C. (2007). Cultural evolution: Interpersonal influence, issue importance, and the development of shared attitudes in college residence halls. Personality and Social Psychology Bulletin, 33(10), 13271339.

Deardorff, D. K. (Ed.). (2009). The Sage handbook of intercultural competence, London: Sage Publications.

Dunbar, R. I. (1992). Neocortex size as a constraint on group size in primates. Journal of Human Evolution, 22(6), 469-493.

Earley, C. P., \& Mosakowski, E. (2000). Creating hybrid team cultures: An empirical test of transnational team functioning. Academy of Management Journal, 43(1), 26-49.

Fu, F., Tarnita, C. E., Christakis, N. A., Wang, L., Rand, D. G., \& Nowak, M. A. (2012). Evolution of in-group favoritism. Scientific Reports, 2, 460.

Hart Research Associates. (2016). Recent trends in general education design, learning outcomes, and teaching approaches: Key findings from a survey among administrators at AAC\&U member institutions. Retrieved from https://www.aacu.org/about/2015-membersurvey

Imai, L., \& Gelfand, M. J. (2010). The culturally intelligent negotiator: The impact of cultural intelligence (CQ) on negotiation sequences and outcomes. Organizational Behavior and Human Decision Processes, 112(2), 83-98.

Kealey, D.J. (1996). The challenge of international personnel selection. In D. Landis \& R.S. Bhagat (Eds.), Handbook of intercultural training ( $2^{\text {nd }}$ ed.) (pp. 81-105). Thousand Oaks, CA: Sage Publications.

Kidd, D. C., \& Castano, E. (2013). Reading literary fiction improves theory of mind. Science, 342(6156), 377-380.

King, P. M., \& Baxter Magolda, M. B. (2005). A developmental model of intercultural maturity. Journal of College Student Development, 46(6), 571592. 
King, P. M., Brown, M. K., Lindsay, N. K., \& VanHecke, J. R. (2007). Liberal arts student learning outcomes: An integrated approach. About Campus, 12(4), 2-9.

King, P. M., Perez, R. J., \& Shim, W. J. (2013). How college students experience intercultural learning: Key features and approaches. Journal of Diversity in Higher Education, 6(2), 69-83.

Krueger, J. (1998). Enhancement bias in descriptions of self and others. Personality and Social Psychology Bulletin, 24(5), 505-516.

Lee, A., Poch, R., Shaw, M., \& Williams, R. (2012). Engaging diversity in undergraduate classrooms: A pedagogy for developing intercultural competence (ASHE Higher Education Report, 38(2)). San Francisco, CA: Jossey-Bass.

Leung, K., Ang, S., \& Tan, M. L. (2014). Intercultural competence. Annual Review of Organanizational Psycholology and Organizational Behavior, 1(1), 489519.

Mahajan, N., \& Wynn, K. (2012). Origins of "us" versus "them": Prelinguistic infants prefer similar others. Cognition, 124(2), 227-233.

McFarland, S., Webb, M., \& Brown, D. (2012). All humanity is my ingroup: A measure and studies of identification with all humanity. Journal of Personality \& Social Psychology, 103(5), 830-853.

Mol, S. T., Born, M. P., Willemsen, M. E., \& Van Der Molen, H. T. (2005). Predicting expatriate job performance for selection purposes: A quantitative review. Journal of Cross-cultural Psychology, 36(5), 590-620.

Perez, R. J., Shim, W., King, P. M., \& Magolda, M. B. B. (2015). Refining King and Baxter Magolda's model of intercultural maturity. Journal of College Student Development, 56(8), 759-776.

Perry, L. B., \& Southwell, L. (2011). Developing intercultural understanding and skills: Models and approaches. Intercultural Education, 22(6), 453-466.

Plaut, V. C., Thomas, K. M., \& Goren, M. J. (2009). Is multiculturalism or color blindness better for minorities? Psychological Science, 20(4), 444-446.

Redmond, M. V. (2000). Cultural distance as a mediating factor between stress and intercultural communication competence. International Journal of Intercultural Relations, 24(1), 151-159.

Redmond, M. V., \& Bunyi, J. M. (1993). The relationship of intercultural communication competence with stress and the handling of stress as reported by international students. International Journal of Intercultural Relations, 17(2), 235-254.

Santiesteban, I., White, S., Cook, J., Gilbert, S. J., Heyes, C., \& Bird, G. (2012). Training social cognition: From imitation to theory of mind. Cognition, 122(2), 228-235. 
Sedikides, C., \& Strube, M. J. (1995). The multiply motivated self. Personality and Social Psychology Bulletin, 21(12), 1330-1335.

Shapiro, S. L., Schwartz, G. E., \& Bonner, G. (1998). Effects of mindfulness-based stress reduction on medical and premedical students. Journal of Behavioral Medicine, 21(6), 581-599.

Shi, X., \& Franklin, P. (2014). Business expatriates' cross-cultural adaptation and their job performance. Asia Pacific Journal of Human Resources, 52(2), 193-214.

Simkhovych, D. (2009). The relationship between intercultural effectiveness and perceived project team performance in the context of international development. International Journal of Intercultural Relations, 33(5), 383390.

Stahl, G. K., Maznevski, M. L., Voigt, A., \& Jonsen, K. (2010). Unraveling the effects of cultural diversity in teams: A meta-analysis of research on multicultural work groups. Journal of International Business Studies, 41(4), 690-709.

Stone, N. (2006). Conceptualising intercultural effectiveness for university teaching. Journal of Studies in International Education, 10(4), 334-356.

Strohmeier, D., Gradinger, P., \& Wagner, P. (2017). Intercultural competence development among university students from a self-regulated learning perspective: Theoretical model and measurement. Zeitschrift für Psychologie, 225(1), 85-94.

Van Der Zee, K. I., \& Van Oudenhoven, J. P. (2000). The Multicultural Personality Questionnaire: A multidimensional instrument of multicultural effectiveness. European Journal of Personality, 14(4), 291-309.

Varnum, M. E., \& Grossmann, I. (2017). Cultural change: The how and the why. Perspectives on Psychological Science, 12(6), 956-972.

Ward, C., Wilson, J., \& Fischer, R. (2011). Assessing the predictive validity of cultural intelligence over time. Personality and Individual Differences, 51(2), 138-142.

Wynveen, C. J., Kyle, G. T., \& Tarrant, M. A. (2012). Study abroad experiences and global citizenship: Fostering proenvironmental behavior. Journal of Studies in International Education, 16(4), 334-352.

Zimmermann, J., \& Neyer, F. J. (2013). Do we become a different person when hitting the road? Personality development of sojourners. Journal of Personality \& Social Psychology, 105(3), 515-530.

\section{Author Contact}

Brian W. Haas, bhaas@uga.edu 
Department of Psychology, 125 Baldwin Street, University of Georgia, Athens, Georgia, 30602. U. S. A. 